\title{
Factors associated with the risk of fall in adults in the postoperative period: a cross-sectional study
}

\author{
Luciana Regina Ferreira da Mata ${ }^{1}$ \\ Cissa Azevedo² \\ Aryanne Gabrielle Policarpo ${ }^{3}$ \\ Juliano Teixeira Moraes ${ }^{4}$
}

Objective: to assess the factors associated with the risk of fall in patients undergoing surgical procedures. Method: quantitative and cross-sectional study carried out with 257 adult patients in a hospital in the state of Minas Gerais, Brazil. Data were collected using the sociodemographic and clinical questionnaire, the Morse Fall Scale, and the Quality of Recovery Score. Data were submitted to descriptive statistical analysis and multinomial logistic regression. The level of significance was set at 0.05 . Results: $35.4 \%$ of patients had high risk of falls, $38.9 \%$ had moderate risk and $25.7 \%$ had low risk. The mean value in the surgical recovery scale was 175.37 points and no patient presented poor surgical recovery. Regarding the results of the bivariate analysis, it was found that age $(p<0.001)$, SAH $(p<0.001)$ and diabetes $(p=0.017)$ were positively associated with high risk of fall, whereas cancer $(p=0.004)$ was positively associated with moderate risk of fall. Surgical recovery $(p=0,008)$ was inversely associated with high risk of fall. Conclusion: the results of this study allowed the identification of five factors associated with the risk of fall in adults in the postoperative hospital stay. These findings may support the planning of nursing actions aimed at preventing the risk of fall in the postoperative period.

Descriptors: Accidental Falls; Patient Safety; Perioperative Nursing.

\footnotetext{
${ }_{1}^{1}$ PhD, Adjunct Professor, Universidade Federal de São João del-Rei, Divinópolis, MG, Brazil.

2 Doctoral student, Escola de Enfermagem, Universidade Federal de Minas Gerais, Belo Horizonte, MG, Brazil. Researcher, Universidade Federal de São João del-Rei, Divinópolis, MG, Brazil.

${ }^{3}$ Resident in Obstetric Nursing, Hospital Sofia Feldman, Belo Horizonte, MG, Brazil.

${ }^{4}$ PhD, Adjunct Professor, Universidade Federal de São João del-Rei, Divinópolis, MG, Brazil.
}

\section{How to cite this article}

Mata LRF, Azevedo C, Policarpo AG, Moraes JT. Factors associated with the risk of fall in adults in the postoperative period: a cross-sectional study. Rev. Latino-Am. Enfermagem. 2017;25:e2904. [Access DOI: http://dx.doi.org/10.1590/1518-8345.1775.2904. ]; Available in: 


\section{Introduction}

Falls and their resulting injuries have a significant impact on the physical, mental and social health of patients. The hospital stay of individuals who fall may be extended for 12.3 more days on average, and the occurrence of such incidents may increase hospital costs by up to $61 \%{ }^{(1)}$. Globally, about $30 \%$ of elderly people fall at least once a year. Although falls are not necessarily indicators of a poor health condition, their consequences may predispose individuals to serious

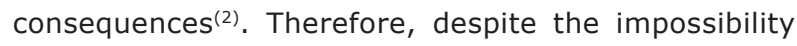
of completely avoiding the risk of falls, the importance of reducing this risk should be considered, especially through a multidisciplinary assessment of the patient $^{(3)}$.

The definition of fall, according to the American Geriatrics Society, "an unexpected displacement of the body to a lower level than the initial position without loss of consciousness"(4). In the United States, falls prevalence rate varies from 3.3 to 11.5 falls per thousand patients per day, with $50 \%$ of hospitalized patients being considered at risk of falls. The resulting injuries can occur in $30-50 \%$ of cases, of which $6 \%$ are serious injuries such as fractures, bruising, bleeding and even death ${ }^{(1,5)}$. Moreover, injuries resulting from falls are the fifth most common cause of death among elderly in the United Kingdom and it is estimated that such an incident will result in more than 200,000 hospitalizations annually, and of these, $78 \%$ are in the age group over 75 years $^{(4)}$.

In Brazil, data from a bulletin published in November 2016 by the National Health Surveillance Agency (ANVISA) on health-related incidents identified a total of 9,423 care failures, of which 3,600 (38.2\%) are falls-related. Therefore, falls are the second leading cause of notifications of incidents. According to ANVISA, "loss of balance" represented $54.8 \%$ of notifications, and in relation to the environmental factors involved in the occurrence of falls, it was observed that falls involving the furniture "Bed" accounted for $38.6 \%$ of notifications, with $28.8 \%$ occurring in the bathroom ${ }^{(6)}$.

Falls are classified into three different types, according to the causal factor of the incident. Accidental fall is that occurring when the patient slips or stumbles, usually caused by factors associated with environment. Anticipated physiological fall is the so-called predictable fall and occurs when the patient presents with signs and symptoms that indicate a probability to fall. In addition, the risk of these falls may be assessed by means of standardized instruments. The so-called unanticipated physiologic fall can be defined as unpredictable and is associated with the presence of fainting and convulsions $^{(7)}$.

Regarding the main risk factors related to falls, it can mentioned the demographic factor, which includes children under five years old and elderly over 65 years; psycho-cognitive factor, such as the presence of depression or anxiety; factors related to health problems, such as prior cerebrovascular accident, bladder and/or intestinal incontinence, postural hypotension, dizziness, arthritis, osteoporosis and metabolic disorders; functional factors such as muscle weakness and even lower limb amputation; and no less important, there are factors related to sensory impairment, body balance, use of certain medications, severe obesity and prior history of falls. Furthermore, it is worth noting that environmental aspects and human resources are identified as risk factors for fall(8-9).

On the other hand, in the context of Patient Safety, more specifically in the context of surgical patient, it is important to assess not only the risk of falls that these individuals are exposed, but also the quality of the physical recovery of the individual submitted to the surgical procedure, which consequently may represent a risk factor for fall.

Surgical recovery is understood as the time in which the individual strives to regain his independence and consequently achieves his return to activities of daily living. Despite the ease of identifying the beginning of a surgical recovery, its end is still uncertain, since several factors capable of affecting surgical recovery may occur during this process in a positive or negative way. These factors include unpleasant physical symptoms, disturbances in emotional well-being, prior history of recovery, recovery time, existence or non-existence of adequate and regular information, and support provided to patient by his family or by the health professionals ${ }^{(10)}$.

Regarding the association between the risk of fall and surgical recovery, it is important to consider the possible influence of aspects such as surgery size and even the purpose of the surgical procedure. The classification of surgical procedures according to some criteria such as cardiavascular risk and their purpose is important for the determination of the demand for care to the individual. The classification according to cardiovascular risk considers the risk of loss of fluids and blood during surgery, being categorized as: small surgery - when the chance of loss of fluids and blood is minimal; medium sized surgery - there is an intermediate-level probability; and large surgery - there is a high probability of this loss $^{(11)}$. As regards the classification by purpose, surgery can be curative, restorative, palliative, diagnostic and reconstructive/plastic ${ }^{(12)}$. 
In view of the above and the scarcity of nursing studies about the risk of fall in the postoperative period and its probable relation with surgical recovery, it becomes relevant to assess the risk of falls in this clientele. It is known that the use of instruments validated at international level has become a concrete way of planning interventions that may improve the quality of provided care and even contribute to the implementation of the Nursing Process ${ }^{(13)}$. Therefore, the aim of this study was to assess the factors associated with the risk of fall in patients undergoing surgical procedures.

\section{Methods}

\section{Procedure and sampling}

Cross-sectional study carried out with patients hospitalized and undergoing surgical procedure in a large hospital in the state of Minas Gerais, Brazil. Data were collected from July to October 2015 and participants were selected according to the following inclusion criteria: adults hospitalized at the hospital surgical units; have undergone surgical procedure for treatment, except orthopedic surgeries; have cognitive ability to participate, assessed by means of the mini mental state examination, considering the cut-off points recommended by the authors of the instrument ${ }^{(14)}$. Patients in late postoperative period were excluded.

Sample size was calculated based on the statistical test for simple random sampling from a finite population, considering the proportion of risk of falls in the population of interest $(12.4 \%)^{(15)}$, with a confidence interval of 95 $\%$ and a margin of error of 0.05 points, which resulted in a minimum sample size of 245 patients.

The researchers carried out data collection by means of individual interviews and consulting the patient's medical records. Three instruments were used: the sociodemographic and clinical questionnaire, the scale for the risk of fall (Morse Fall Scale)(16) and the scale of surgical recovery (Quality of Recovery Score) $)^{(17)}$.

\section{Instruments}

The sociodemographic and clinical questionnaire, prepared by the authors, included open and closed questions for collection of data regarding age, skin color, education, marital status, professional occupation, medical diagnosis, surgery size (small, medium and large)(11), purpose of the surgical procedure (curative, reparative, palliative, diagnostic and reconstructive/ plastic)(12), presence of comorbidities and signs/ symptoms (pain, inappetence, weakness/fatigue, lack of sleep, diarrhea and urinary incontinence).
The Morse Fall Scale (MFS) ${ }^{(19)}$ translated and adapted into Brazilian Portuguese ${ }^{(16)}$ was the instrument used to assess the risk of falls. This scale is composed of six items to which are assigned different scores: history of falls - history of fall in the last three months (zero point) or not (25 points); secondary diagnosis - more than one medical diagnosis (15 points) or not (zero point); assistance in walking - does not use/fully bedridden/aided by a health professional (zero points), uses crutches/canes/walkers (15 points), holds on the furniture/wall (30 points); intravenous therapy salinized or heparinized endovenous device - yes (20 points) or not (zero point); walking - normal/no walking/ bedridden/wheelchair (zero point), weak (10 points), compromised/staggering (20 points); and mental status - oriented/able as to his ability/ limitation (zero point) or overestimate ability/forget his limitations (15 points).

The sum of the six MFS items may range from 0 to 125 points. Scores between zero and 24 represent low risk of fall during hospitalization, requiring basic nursing care. Scores between 25 and 44 points represent moderate risk of fall and therefore require the implementation of basic interventions to prevent possible falls. Patients classified with 45 points and over have a high risk of fall, that is, they need planned and implemented actions in order to prevent falls ${ }^{(16)}$.

The Portuguese version ${ }^{(17)}$ of the Quality of Recovery Score $(\mathrm{Q} o \mathrm{R}-40)^{(20)}$ was used to measure the quality of recovery from the surgical procedure. The instrument addresses the quality of patient recovery from surgical and anesthetic procedures in the postoperative period. It has 40 questions distributed in five dimensions: emotional state $(n=9)$, physical comfort $(n=12)$, psychological support $(n=7)$, physical independence and pain $(n=7)$.

This questionnaire has two parts: $\mathrm{A}$ and $\mathrm{B}$. In part $A$, the questions indicate positive aspects and in part $B$, the questions indicates negative aspects. In part $A$, the terms "none of the time", "some moments", "frequently", "most of the time" and "all of the time" receive the scores 1, 2, 3, 4 and 5 respectively. In part B there is the inverse scoring. The maximum score for QoR-40 is 200 (excellent quality of recovery), and the minimum score is 40 (poor quality of recovery) ${ }^{(17)}$. The Cronbach's alpha of the sample was 0.79 , showing a good internal consistency of the instrument ${ }^{(21)}$.

\section{Data analysis}

Data processing and analysis were performed using the softwares Statistical Package for Social Science (SPSS), version 21.0 for Windows, and Stata 11. The results obtained for the explanatory variables 
(sociodemographic and clinical characterization) were analyzed using descriptive statistics, measures of central tendency (mean, median) and variability (standard deviation) for continuous variables, and relative frequency was used for categorical variables. The Shapiro-Wilk test was used to check the normality of the explanatory variables, and those variables with normal distribution were described as mean and standard deviation, and the other variables were expressed as median and interquartile range $\left(\mathrm{p}_{25}-\mathrm{p}_{75}\right)$.

The chi-square test and Fisher's exact test were used to detect possible differences between categorized risk of fall and sociodemographic variables (age, sex, skin color, marital status, education and occupation). The bivariate analysis was performed using simple multinominal logistic regression models, with categorized risk of fall (low risk - reference category; medium risk and high risk) as dependent variable, and as explanatory variables: age, gender, purpose of treatment, surgical size, surgical recovery, pain, presence of systemic arterial hypertension (SAH), diabetes and cancer ${ }^{(8-9,22)}$. The independent variables with p-values lower than $20 \%$ $(p<0.20)$ were indicated by the Backward method and inserted into the multivariate logistic regression model, and those with low significance $(p>0.05)$ were removed one by one from the model. The procedure was repeated until all variables of the model have reached statistical significance $(p<0.05)$.

The national ethical recommendations on human research proposed by the National Health Council were met and the Ethics Committee of the proposing institution approved the research project (CAAE: 37714614.2.3001.5130).

\section{Results}

In total, 257 participants were evaluated, the marjority $(60.3 \%)$ were female, the mean age was 54 years (41-64) and the average years of schooling was seven years (4-11). Regarding clinical data, the most prevalent medical diagnosis was cancer $(47.1 \%)$. The main types of cancer were: breast $(20.7 \%)$, cervix $(19.0 \%)$, prostate $(17.3 \%)$ and thyroid $(13.2 \%)$. Two other medical diagnoses were cholelithiasis (9.3\%) and inguinal hernia (8.6\%). Regarding the surgical size, the majority $(72.0 \%)$ of the surgeries were of medium size. Regarding the classification of surgeries, $27.6 \%$ were considered as general surgeries, $25.3 \%$ were gynecological, $16 \%$ were urological and $14.4 \%$ were head and neck. Regarding the purpose of the surgical procedure, $87.9 \%$ were curative. Regarding the presence of comorbidities, the most prevalent were: SAH $(37.0 \%)$, diabetes $(12.5 \%)$, cardiopathy $(3.6 \%)$ and hypothyroidism (2.3\%). As for the presence with signs/symptoms in the sample, the most prevalent were pain (64.2\%) and weakness/fatigue (41.6\%).

Table 1 shows the sociodemographic and clinical characteristics distributed according to the categories of the variable risk of fall.

It was observed that the variables age, schooling, occupation, SAH, diabetes and cancer presented statistically significant differences between groups $(p<0.05)$.

The mean obtained for the risk of fall using the MFS scale was 34.75 points ( $S D=15.49$ ), with $25.7 \%$ of the patients presenting a low risk of falls, $38.9 \%$ moderate risk and $35.4 \%$ high risk.

Regarding surgical recovery, the mean value was 175.37 points $(S D=11.40)$, with a minimum of 128 and a maximum of 195 points. These results indicate that no patient had a poor surgical recovery.

Table 2 describes simple multinominal regression analysis whose dependent variable is the risk of fall and the explanatory variables are age, purpose of surgical procedure, surgical size, surgical recovery, presence of SAH, diabetes and cancer. For modeling purposes, two variables chosen at the univariate stage (schooling and occupation) were not used in the bivariate analysis, as they did not have clinical and scientific importance for the risk of falls.

The variables purpose of surgical procedure and surgical size were not associated with risk of fall $(p>0.05)$. On the other hand, age (OR: 1.05, CI: 1.031.07) and surgical recovery (OR: 0.95, CI: 0.93-0.99) were positively and inversely associated with high risk of fall, respectively. The variables SAH (OR: 11.64, CI: 5.44-24.92), diabetes (OR: 24.62, IC3.24-187.08) and cancer (OR: 3.84, CI: 93-7.66) were positively associated with high risk of falls.

Table 3 shows the results of the multinominal Regression Model for risk of fall.

Regarding the results of the multinominal regression model for the categorized risk of fall, with low risk as reference category, the following results were obtained: each increase of one year in age increases the chance of having high risk of fall when compared to low risk; each increase of one point in the scale of surgical recovery there is a $5 \%$ decrease in the chance of having high risk of fall when compared to low risk; hypertensive patients are 8.57 times more likely to have high risk of fall when compared to non-hypertensive patients; diabetic patients are 13.35 times more likely to have high risk of fall when compared to non-diabetics; and, finally, patients with a diagnosis of cancer are 2.86 times more likely to have moderate risk of fall when compared to patients who do not have a diagnosis of cancer. 
Table 1 - Sociodemographic and clinical characteristics grouped according to categories of the risk of fall. Divinopolis, MG, Brazil, 2015

\begin{tabular}{|c|c|c|c|c|}
\hline & \multirow[b]{2}{*}{$\begin{array}{c}\text { Low risk }^{*} \\
25.7 \% \\
(\mathrm{n}=66) \\
\end{array}$} & \multirow[b]{2}{*}{$\begin{array}{c}\text { Medium risk* } \\
38.9 \% \\
(n=100)\end{array}$} & \multirow[b]{2}{*}{$\begin{array}{c}\text { High risk* } \\
35.4 \% \\
(\mathrm{n}=91)\end{array}$} & \multirow[b]{2}{*}{$P$ value } \\
\hline Variable & & & & \\
\hline Sex & & & & $0.670^{\dagger}$ \\
\hline Female & 37 (23.9) & $63(40.6)$ & $55(35.5)$ & \\
\hline Male & $29(28.4)$ & $37(36.3)$ & $36(35.3)$ & \\
\hline Age & & & & $0.001^{\ddagger}$ \\
\hline Between 18 and 39 & $20(33.3)$ & $31(51.7)$ & $9(15.0)$ & \\
\hline Between 40 and 59 & $30(29.4)$ & $37(36.3)$ & $35(34.3)$ & \\
\hline Between 60 and 79 & 15 (17.6) & $30(35.3)$ & $40(47.1)$ & \\
\hline 80 years and over & $1(10.0)$ & $2(20.0)$ & $7(70.0)$ & \\
\hline Skin color & & & & $0.751^{\ddagger}$ \\
\hline White & 45 (26.5) & $66(38.8)$ & $59(34.7)$ & \\
\hline Brown & $10(20.4)$ & $18(36.7)$ & $21(42.9)$ & \\
\hline Black & $6(23.1)$ & $12(46.2)$ & $8(30.8)$ & \\
\hline Yellow & $5(41.7)$ & $4(33.3)$ & $3(25.0)$ & \\
\hline Marital status & & & & $0.143^{\ddagger}$ \\
\hline Married & $43(26.5)$ & $63(38.9)$ & $56(34.6)$ & \\
\hline Single & 18 (35.3) & $20(39.2)$ & $13(25.5)$ & \\
\hline Widower & $3(13.0)$ & $9(39.1)$ & $11(47.8)$ & \\
\hline Divorced & $2(9.5)$ & $8(38.1)$ & $11(52.4)$ & \\
\hline Schooling & & & & $<0.001^{\dagger}$ \\
\hline 0 to 4 years & $16(15.4)$ & $34(32.7)$ & $54(51.9)$ & \\
\hline 5 to 10 years & $18(27.7)$ & $31(47.7)$ & $16(24.6)$ & \\
\hline 11 years and over & $32(36.4)$ & $35(39.8)$ & $21(23.9)$ & \\
\hline Occupation & & & & $<0.001^{\dagger}$ \\
\hline Active & $53(33.5)$ & $61(38.6)$ & $44(27.8)$ & \\
\hline Retiree & $13(13.1)$ & $39(39.4)$ & $47(47.5)$ & \\
\hline Pain & & & & $0.818^{+}$ \\
\hline No & $22(23.9)$ & $38(41.3)$ & $32(34.8)$ & \\
\hline Yes & $44(26.7)$ & $62(37.6)$ & $59(35.7)$ & \\
\hline $\mathrm{SAH}^{\S}$ & & & & $<0.001^{\dagger}$ \\
\hline No & $52(39.1)$ & $59(44.4)$ & $22(16.5)$ & \\
\hline Yes & 14 (11.3) & $41(33.1)$ & $69(55.6)$ & \\
\hline Diabetes & & & & $<0.001^{\ddagger}$ \\
\hline No & 65 (28.9) & $94(41.8)$ & $66(29.3)$ & \\
\hline Yes & $1(3.1)$ & $6(18.8)$ & $25(78.1)$ & \\
\hline Cancer & & & & $<0.001^{\dagger}$ \\
\hline No & $49(36.0)$ & $48(35.3)$ & 39 (28.7) & \\
\hline Yes & $17(14.0)$ & $52(43.0)$ & $52(43.0)$ & \\
\hline
\end{tabular}

*The data are $\mathrm{n}(\%)$; + Chi-square test; $¥$ Fisher's exact test; §SAH - systemic arterial hypertension

Table 2 - Simple multinomial regression models for categorized risk of fall (low risk - reference), according to explanatory variables. Divinopolis, MG, Brazil, 2015

\begin{tabular}{|c|c|c|c|c|c|c|}
\hline \multirow{2}{*}{ Variable } & \multicolumn{3}{|c|}{ Medium risk } & \multicolumn{3}{|c|}{ High risk } \\
\hline & $\mathrm{OR}^{*}$ & $\mathrm{Cl}^{+}$ & $P$ value & $O R^{*}$ & $\mathrm{Cl}^{+}$ & $P$ value \\
\hline Age & 1.01 & $0.99-1.03$ & 0.142 & 1.05 & $1.03-1.07$ & $<0.001^{\ddagger}$ \\
\hline \multicolumn{7}{|l|}{ Purpose } \\
\hline Curative & 1 & - & - & 1 & - & - \\
\hline Palliative & 0.68 & - & 1.00 & 21 & - & 0.994 \\
\hline Diagnostic & 2.66 & $0.28-24.61$ & 0.388 & 3.69 & $0.39-35.02$ & 0.254 \\
\hline Reconstructive & 0.96 & $0.20-4.54$ & 0.967 & 2.84 & $0.66-12.12$ & 0.158 \\
\hline Plastic & 0.65 & $0.04-10.83$ & 0.770 & 6.54 & - & 0.990 \\
\hline
\end{tabular}


Table 2 - (continuation)

\begin{tabular}{|c|c|c|c|c|c|c|}
\hline \multirow{2}{*}{ Variable } & \multicolumn{3}{|c|}{ Medium risk } & \multicolumn{3}{|c|}{ High risk } \\
\hline & $\mathrm{OR}^{*}$ & $\mathrm{Cl}^{\dagger}$ & $P$ value & $\mathrm{OR}^{*}$ & $\mathrm{Cl}^{+}$ & $P$ value \\
\hline \multicolumn{7}{|l|}{ Surgical size } \\
\hline Low & 1 & - & - & 1 & - & - \\
\hline Medium & 1.23 & $0.07-20.0$ & 0.884 & 0.53 & $0.47-6.07$ & 0.614 \\
\hline Large & 3.33 & $0.18-58.7$ & 0.411 & 1.61 & $0.13-19.9$ & 0.710 \\
\hline Surgical recovery & 0.97 & $0.94-1.00$ & 0.146 & 0.96 & $0.93-0.99$ & $0.025^{\S}$ \\
\hline \multicolumn{7}{|l|}{ SAH" } \\
\hline No & 1 & - & - & 1 & - & - \\
\hline Yes & 2.58 & $1.26-5.26$ & $0.009^{\S}$ & 11.64 & $5.44-24.92$ & $<0.001^{\ddagger}$ \\
\hline \multicolumn{7}{|l|}{ Diabetes } \\
\hline No & 1 & - & - & 1 & - & - \\
\hline Yes & 4.15 & $0.49-35.28$ & 0.193 & 24.62 & $3.24-187.07$ & $0.002^{\S}$ \\
\hline \multicolumn{7}{|l|}{ Cancer } \\
\hline No & 1 & - & - & 1 & - & - \\
\hline Yes & 3.12 & $1.59-6.14$ & $0.001^{\S}$ & 3.84 & $1.93-7.66$ & $<0.001^{\ddagger}$ \\
\hline
\end{tabular}

*OR - odds ratio; +CI - 95\% confidence interval; $\neq \mathrm{p}<0.001 ; \S \mathrm{p}<0.05 ;|| \mathrm{SAH}$ - systemic arterial hypertension

Table 3 - Results of the multinomial regression model for categorized risk of fall (low risk - reference). Divinopolis, MG, Brazil, 2015.

\begin{tabular}{|c|c|c|c|c|c|c|}
\hline \multirow{2}{*}{ Variable } & \multicolumn{3}{|c|}{ Medium risk } & \multicolumn{3}{|c|}{ High risk } \\
\hline & ORA $^{*}$ & $\mathrm{Cl}^{\dagger}$ & $P$ value & ORA* & $\mathrm{Cl}^{\dagger}$ & $P$ value \\
\hline Age & 1.03 & $0.98-1.05$ & 0.115 & 1.04 & $1.01-1.07$ & $0.001^{\ddagger}$ \\
\hline Surgical recovery & 0.97 & $0.94-1.00$ & 0.094 & 0.95 & $0.92-0.98$ & $0.008^{\S}$ \\
\hline \multicolumn{7}{|l|}{ Systemic arterial hypertension } \\
\hline No & 1 & - & - & 1 & - & - \\
\hline Yes & 2.46 & $1.11-5.48$ & $0.027^{\S}$ & 8.57 & $3.59-20.49$ & $<0.001^{\ddagger}$ \\
\hline \multicolumn{7}{|l|}{ Diabetes } \\
\hline No & 1 & - & - & 1 & - & - \\
\hline Yes & 3.21 & $0.36-28.85$ & 0.298 & 13.35 & $1.59-111.98$ & $0.017^{\S}$ \\
\hline \multicolumn{7}{|l|}{ Cancer } \\
\hline No & 1 & - & - & 1 & - & - \\
\hline Yes & 2.86 & $1.39-5.86$ & $0.004^{\S}$ & 2.21 & $0.98-4.91$ & 0.053 \\
\hline
\end{tabular}

\section{Discussion}

This study demonstrated that five factors are associated with risk of falls in hospitalized adult patients in the postoperative period, which reinforces the fall as a multifactorial event. It is expected that these findings may contribute to the work of nurses, in order to subsidize the planning and implementation of actions aimed at preventing falls in the hospital environment and, consequently, improved patient safety.

Regarding the results obtained using the Morse Scale, whose mean was 34.75 points, that is, moderate risk of fall, similar data were found in the literature. In a study that aimed to identify the predictive value of this instrument in a sample of adult patients hospitalized in the medical clinic, surgical and oncological units, a mean of 31.77 points was obtained(3). Another Brazilian study, whose objective was to analyze the risk factors for falls in the first 48 hours of hospitalization in clinical and surgical units, found an average score of 39.10 points for the MFS, which also indicates a moderate risk of falls(23).

As for surgical recovery, it is noteworthy that the mean was 175.37 points and none of the participants showed a poor quality of surgical recovery. Corroborating these results, other studies also identified similar results with a mean for the quality of surgical recovery ranging from 154 to 192 points ${ }^{(24-27)}$. It is known that postoperative recovery involves several factors that include the reestablishment of the physical, physiological and social functions. Therefore, prediction of a poor quality of surgical recovery is also an indicator to identify patients with a high risk of falls, mainly because poor quality of surgical recovery is associated with high rates of postoperative complications, extension of the hospitalization stay, and more rehospitalizations ${ }^{(28)}$. 
In this context, it should be noted that most indicators of good surgical recovery, such as those related to comfort, physical independence and emotional support, when affected, become important risk factors for falls. In surgical patients, assessment of risk of falls should be carried out at all stages of the process, mainly including the postoperative period, since at this stage the patient may still be on anesthetic effects, with impaired skin integrity, use of catheters and drains, selfcare difficulties, impaired sleep pattern and presence of pain ${ }^{(22)}$. In this context, NANDA-I ${ }^{(18)}$ contemplates the risk of falls in the postoperative recovery period as a physiological risk factor in the nursing diagnosis.

Consideration should also be given to strategies that reduce the risk of falls in surgical patients, such as assessment of the effects of sedatives and anticoagulants, support to unaccompanied patients, evaluation of glycemic levels during long periods of fasting, as well as provision of equipaments to assist in walking for patients with mobility deficits ${ }^{(22)}$.

As for the most frequent comorbidities among patients, it was highlighted SAH. It is known that two important risk factors for falls are blood pressure levels, as well as the use of antihypertensive drugs. In a study aimed at determining the relationship between functional decline and risk of falls in elderly patients, it was observed that in hypertensive patients there was a high risk of falls ${ }^{(29)}$. Furthermore, in another study aimed at analyzing the association between the use of certain drugs and the occurrence of falls, it was observed that patients who used antihypertensive drugs had a higher risk of recurrence for falls, and in some cases this risk was eight times higher when compared to other drugs ${ }^{(30)}$.

Regarding the association between cancer and risk of falls, it is estimated that one in five patients with cancer develops a new risk factor for falls when undergoing chemotherapy, whereas in elderly cancer patients the risk of falls is $17 \%$ higher when compared with young adults ${ }^{(31)}$. Cancer is a disease that shows a close association with the risk of falls, mainly due to certain complications on the feet. Such complications result from the neurotoxicity of chemotherapeutic agents, such as the so-called hand-foot syndrome, an adverse effect that causes pain, edema and redness on the soles of the feet, which can also lead to changes in walking, postural instability and, consequently, increased risk of falls(32). Considering the study sample, it is possible that the treatment of some cancer patients, especially in the case of the breast and uterine cancer, the surgical procedure is associated with chemotherapy ${ }^{(33-34)}$, which enhances the risk for falls.

With regard to diabetes, it is known that diabetic neuropathies are the most prevalent chronic complications of the disease, affecting different parts of the nervous system and are related to various clinical symptoms that include loss of proprioception, weakness, balance changes and consequent instability of walking. Furthermore, it should be considered that the medicines used to treat diabetic neuropathies might cause cognitive function decline, drowsiness and vision problems. Therefore, these aspects highlight the increased risk of falls in diabetic patients, which reinforces the importance of using instruments to assess the risk of such an incident in clinical practice ${ }^{(35)}$.

The lack of studies correlating pain and risk of falls in surgical patients restricts the discussion on this audience. However, a systematic review aimed at identifying the association between pain level and risk of falls in elderly patients, concluded that pain was the most important factor for risk of falls, compared to cognitive capacity, presence of depression, visual impairment and use of sedatives. Therefore, these results suggest the importance of a periodic assessment of pain levels in hospitalized patients, especially considering the occurrence of prior falls, in order to propose interventions that may reduce this incident ${ }^{(36)}$.

It is important to consider that the non-association between pain and the risk of falls observed in this study may be related to the manner in which this fifth vital signal was identified, without the use of a scale, which may have hampered the perception of symptom intensity and the accurate delimitation of the level of pain. The process of pain assessment is broad and involves obtaining information related to the date of onset, location, intensity, duration, periodicity, sensorial and affective qualities of the patient and those factors that initiate, increase or decrease their intensity. Therefore, it is necessary to consider that, due to the subjectivity of this symptom, it becomes relevant to use validated instruments in order to make the classification of this phenomenon more accurate ${ }^{(37)}$.

According to the results of the regression model, there was no association between risk of fall and the variable sex. In the literature, there is no consensus on which sex has the highest frequency of falls and whether this characteristic should be a factor associated with falls ${ }^{(38)}$. Studies that consider a higher incidence of falls in males ${ }^{(39-42)}$ argue that this relationship may be due to a masculine culture that does not accept help for certain tasks, such as getting out of bed and walking. There are studies that mention women as being more prone to falls ${ }^{(43-45)}$, which is explained by a higher frequency of osteoarthrosis in women, decrease muscular strength, stronger connection with domestic activities, hormonal changes such as reduction of estrogen, and the consequent loss of bone mass. It is noteworthy that 
NANDA-I does not contemplate female sex as a risk factor for falls in the nursing diagnosis since its 20072008 edition $^{(46)}$.

In terms of age, $37 \%$ of patients in this study were older than 60 years, and in the study sample, these two variables showed a significant association, so that increasing age implies an increased risk of falls. It is known that the fall phenomenon and the physical and psychic problems derived from aging have been a recurring concern of the health institutions, since functional and structural alterations may compromise psychomotor development, as well as decrease muscular strength, walking, stability and dynamics articulate ${ }^{(29)}$. It is also important to consider the increase of chronicdegenerative diseases among the elderly and the side effects of drugs that favor the occurrence of falls(31). In NANDA-I ${ }^{(18)}$, the risk factor "age over 65 years" is present in the risk of falls of the nursing diagnosis, which reinforces the importance of a careful assessment by the nurse during the survey on the changes related to age and planning of actions that may mitigate this risk.

As a limitation of this study, there is the fact that only sociodemographic and clinical aspects were considered in the assessment of the factors associated with fall. However, it is known the importance of environmental factors, the work process and the organization of services, for example, human resources as possible predictors of falls. Another limitation is attributed to the small number of publications that used the MFS instrument, which restricted the association of the findings of this study with other realities, based on the same assessment strategy. It is also important to note that MFS was submitted to the cross-cultural adaptation process for its use in Brazil(16), although, there is still no publication mentioning the accuracy analysis of the Brazilian version of this instrument.

\section{Conclusion}

The results of this study allowed the identification of five factors associated with the risk of falls in adult patients undergoing surgical procedures.

Emphasis is placed on the importance of health institutions in minimizing the occurrence of falls, especially regarding the adoption of measures such as the use of non-slip floors, equipaments to assist in walking, presence of side railings in the beds, as well as guidelines for patients and caregivers.

Finally, it is expected that the results of this study may increase knowledge about issues related to patient safety and clinical nursing practice. This study reinforces the importance of assessing surgical patients with regard to the risk of falls and the implementation of pre- and postoperative interventions to prevent this incident, since it can cause serious problems such as injury, prolonged hospitalization, increased hospital costs or even death. Therefore, based on the associated factors found, nurses of the surgical hospitalization sectors will be able to plan nursing interventions for the risk of falls.

\section{References}

1. Avanecean D, Calliste D, Contreras T, Lim Y, Fitzpatrick A. Effectiveness of patient-centered interventions on falls in the acute care setting: a quantitative systematic review protocol [Internet]. The Joanna Briggs Institute; 2017 [cited Jan 31, 2017]; 55-65. Available from: http://journals. Iww.com/jbisrir/Abstract/2017/01000/ Effectiveness_of_patient_centered_interventions_ on.9.aspx

2. Gazibara T, Kurtagic I, Kisic-Tepavcevic D, Nurcovic S, Kovacevic N, Gazibara T, et al. Falls, risk factors and fear of falling among persons older than 65 years of age. Psychogeriatrics. 2017 [cited Jan 31, 2017]; 1-9. Available from: http://onlinelibrary.wiley.com/ doi/10.1111/psyg.12217/epdf

3. Nassar N, Helou N, Madi C. Predicting falls using two instruments (the Hendrich Fall Risk Model and the Morse Fall Scale) in an acute care setting in Lebanon. J Clin Nurs. 2013 [cited Feb 15, 2016]; 23:1620-9. Available from: http://onlinelibrary. wiley.com/doi/10.1111/ jocn.12278/pdf

4. Keny RA, Romero-Ortuno R, Cogan L. Falss. Medicine. [Internet]. 2012 [cited March 15, 2016];41(3):155-9. Available from: http://www.sciencedirect.com/science/ article/pii/S135730391200299X

5. Fields J, Alturkistani T, Kumar N, Kanuri A, Salem DN, Munn $S$, et al. Prevalence and cost of imaging in inpatient falls: the rising cost of falling. Clinicoecon Outcomes Res. 2015 [cited May 16, 2016]; 7:2816. Available from: http://www.ncbi.nlm.nih.gov/pmc/ articles/PMC4461128/

6. Agência Nacional de Vigilância Sanitária. Boletim Segurança do Paciente e Qualidade em Serviços de Saúde - Incidentes Relacionados à Assistência à Saúde - 2015 [Internet]. Brasília (DF); 2016. 30 p. [Acesso 3 jan 2017]. Disponível em: http://www20.anvisa. gov.br/segurancadopaciente/index.php/publicacoes/ item/13-boletim-seguranca-do-paciente-e-qualidadeem-servicos-de-saude-n-13-incidentes-relacionados-aassistencia-a-saude-2015

7. Costa-Dias MJM, Ferreira PL. Escalas de avaliação de risco de quedas. Referência. [Internet]. 2014 [Acesso 3 jan 2017]; 2: 153-61. Disponível em: http://www. scielo.mec.pt/pdf/ref/vserIVn2/serIVn2a16.pdf 
8. Lunsford B. Assessing your patients' risk for falling. Am J Nurs. [Internet]. 2015 [cited Feb 3, 2017]; 10(7): 29-31. Available from: ttps://americannursetoday.com/ wpcontent/uploads/2015/07/ant7-Falls-630_FULL.pdf 9. Pi HY, Gao Y, Wang J, Hu MM, Nie D, Peng PP. Risk Factors for In-Hospital Complications of Fall-Related Fractures among Older Chinese: A Retrospective Study. BioMed Res Int. [Internet]. 2016 [cited Jan 3, 2017]; 2016: 1-11. Available from: https://www.ncbi.nlm.nih.gov/pmc/ articles/PMC5220428/pdf/BMRI20168612143.pdf

10. Yaghoobi S, Hamidfar M, Lawson DM, Fridlund B, Myles PS, Pakpour AH. Validity and reliability of the Iranian version of the Quality of Recovery-40 questionnaire. Anesth Pain Med. [Internet]. 2015 [cited Jan 3, 2017]; 5(2):e20350. Available from: https:// www.ncbi.nlm.nih.gov/pmc/articles/PMC4394674/pdf/ aapm-05-02-20350.pdf

11. Duceppe E, Parlow J, McDonald P, Lyons K, McMullen M, Srinathan $S$, et al. Canadian Cardiovascular Society Guidelines on Perioperative Cardiac Risk Assessment and Management for Patients Who Undergo Noncardiac Surgery. Can J Cardiol. [Internet]. 2017 [cited Jan 31, 2017]; 33: 17e32. Available from: http://www.sciencedirect.com/science/article/pii/ S0828282X16309801

12. National Cancer Institute. Types of Surgery [Internet]. USA: Department of Health \& Human Services; c2016 [cited Feb 7, 2017]. Available from: https://training. seer.cancer.gov/treatment/surgery/types/

13. Lopes MV, Silva VM, Araujo TL, Guedes NG, Martins LC, Teixeira IX. Instrument for evaluation of sedentary lifestyle in patients with high blood pressure. Rev Bras Enferm. [Internet]. 2015; [cited Feb 7, 2017]; 68(3):445-51. Available from: http://www.scielo.br/ pdf/reben/v68n3/0034-7167-reben-68-03-0445.pdf

14. Bertolucci PH, Brucki SM, Campacci SR, Juliano Y. O mini-exame do estado mental em uma população geral: impacto da escolaridade. Arq Neuropsiquiatr. [Internet]. 1994 [Acesso 16 mai 2016]; 52:1-7. Disponível em: http://www.scielo.br/pdf/anp/v52n1/01.pdf

15. Diccini S, Pinho PG, Silva FO. Assessment of risk and incidence of falls in neurosurgical inpatients. Rev LatinoAm. Enferm. [Internet]. 2008 [cited May 16, 2016]; 16(4): 752-7. Available from: http://www.scielo.br/pdf/ rlae/v16n4/16.pdf

16. Urbanetto JS, Creutzberg M, Franz F, Ojeda BS, Gustavo AS, Bittencourt HR. Morse Fall Scale: translation and transcultural adaptation for the Portuguese language. Rev Esc Enferm USP. [Internet]. 2013 [cited May 16, 2016]; 47(3): 569-75. Available from: http:// www.scielo.br/pdf/reeusp/v47n3/en_0080-6234reeusp-47-3-00569.pdf
17. Eduardo AHA, Santos CB, Carvalho AMP, Carvalho EC. Validation of the Brazilian version of the Quality of Recovery - 40 Item questionnaire. Acta Paul Enferm. [Internet]. 2016 [cited Jan 31, 2017]; 29(3):253-9. Available from: http://www.scielo.br/pdf/ape/v29n3/ en_1982-0194-ape-29-03-0253.pdf

18. Diagnósticos de Enfermagem da NANDA: definições e classificação 2015-2017/ [NANDA Internacional]. Porto Alegre: Artmed; 2015. 488 p.

19. Morse JM, Morse BM, Tylko S. Development of a scale to identify the fall-prone patient. Can J Aging. [Internet]. 1989 [cited Feb 7, 2017]; 8:(3):6677. Available from: https://www.cambridge.org/ core/journals/canadian-journal-on-aging-la-revuecanadienne-du-vieillissement/article/developmentof-a-scale-to-identify-the-fall-prone-patient/ A0CDFA5381DEC8DA4D7E7A1B1A74692E

20. Myles PS, Weitkamp B, Jones K, Melick J, Hensen S. Validity and reliability of a postoperative quality of recovery score: the QoR-40. $\mathrm{Br}$ J Anaesth. [Internet]. 2000 [cited Feb 7, 2017]; 84(1):11-5. Available from: https://academic.oup.com/bja/article/84/1/11/266065/ Validity-and-reliability-of-a-postoperative

21. Tavakol M, Dennick R. Making sense of Cronbach's alpha. Int ] Med Educ. [Internet]. 2011 [cited May 16, 2016];2:53-5. Available from: http://www.ncbi.nlm.nih. gov/pmc/articles/PMC4205511/pdf/ijme-2-53.pdf

22. Namara S. Reducing Fall Risk for Surgical Patients. AORN J. [Internet]. 2011 [cited May 16, 2016];93(3):3904. Available from: http://www.aornjournal.org/article/ S0001-2092(10)01307-4/pdf

23. Remor $\mathrm{CP}$, Cruz $\mathrm{CB}$, Urbanetto JS. Analysis of fall risk factors in adults within the first 48 hours of hospitalization. Rev Gaúcha Enferm. [Internet]. 2014 [cited Jan 31, 2017]; 35(4):28-34. Available from: http://www.scielo.br/pdf/rgenf/v35n4/1983-1447rgenf-35-04-00028.pdf

24. Shida D, Wakamatsu K, Tanaka Y, Yoshimura A, Kawaguchi M, Miyamoto $S$, et al. The postoperative patient-reported quality of recovery in colorectal cancer patients underenhanced recovery after surgery using QoR-40. BMC Cancer. [Internet]. 2015 [cited May 16, 2016];15(799):1-6. Available from: http://www.ncbi. nlm.nih.gov/pmc/articles/PMC4624174/

25. Sveinsdottir $H$, Borgthorsdottir T, Asgeirsdottir MT, Albertsdottir K, Asmundsdottir LB. Recovery After Same-Day Surgery in Patients Receiving General Anesthesia: A Cohort Study Using the Quality of Recovery-40 Questionnaire. J Perianesth Nurs. 2016 [cited Feb 6, 2017]; 31(6): 475-84. Available from: http://www.sciencedirect.com/science/article/pii/ S1089947216000411 
26. Guimarães-Pereira L, Costa M, Sousa G, Abelha F. Quality of recovery after anaesthesia measured with QoR-40: a prospective observational study. Rev Bras Anestesiol. [Internet]. 2016 [cited Feb 7, 2017]; 66(4): 369-75. Available from: http://www.scielo.br/pdf/rba/ v66n4/0034-7094-rba-66-04-0369.pdf

27. Moro ET, Silva MAN, Couri MG, Issa DS, Barbieri JM. Quality of recovery from anesthesia in patients undergoing orthopedic surgery of the lower limbs. Rev Bras Anestesiol. [Internet]. 2016 [cited Feb 7, 2017]; 66(6): 642-50. Available from: http://www.sciencedirect. com/science/article/pii/S003470941600026X

28. Yeh HF, Shao JH, Li CL, Wu CC, Shyu YIL. Predictors of postoperative falls in the first and second postoperative years among elderly hip fracture patients. J Clin Nurs. [Internet]. 2016 [cited Feb 7, 2017]; 2-32. Available from: http://onlinelibrary.wiley.com/doi/10.1111/ jocn.13743/epdf

29. Chu JJ, Chen XJ, Shen SS, Zhang XF, Chen LY, Zhang $\mathrm{JM}$, et al. A poor performance in comprehensive geriatric assessment is associated withincreased fall risk in elders with hypertension: a cross-sectional study. J Geriatric Cardiol. [Internet]. 2015 [cited May 16, 2016]; 12:1138. Available from: http://www.ncbi.nlm.nih.gov/pmc/ articles/PMC4394325/

30. Costa-Dias MJ, Oliveira AS, Martins T, Araújo F, Santos AS, Moreira CN, et al. Medication fall risk in old hospitalized patients: a retrospective study. Nurse Educ Today. [Internet]. 2014 [cited May 16, 2016];34:171-6. Available from: http://www.ncbi.nlm.nih.gov/pubmed/23769987 31. Wildes TM, Dua P, Fowler SA, Miller JP, Carpenter $C R$, Avidan MS, et al. Systematic review of falls in older adults with cancer. J Geriatr Oncol. [Internet]. 2015 [cited Feb 7, 2017]; 6:70-83. Available from: https:// www.ncbi.nlm.nih.gov/pmc/articles/PMC4297689/pdf/ nihms-640487.pdf

32. Ungar A, Rafanelli M. My older patient with cancer reports falls: What should I do?. J Geriatric Oncol. [Internet]. 2015 [cited Feb 6, 2017]; 6: 419-23. Available from: http://www.sciencedirect.com/science/ article/pii/S1879406815000995

33. Almeida TG, Cunha IW, Maciel GAR, Baracat EC, Carvalho KC. Clinical and molecular features of uterine sarcomas. MedicalExpress. [Internet]. 2014 [cited Feb 8, 2017]; 1(6):291-7. Available from: http://www.scielo.br/ pdf/medical/v1n6/2318-8111-medical-01-06-0291.pdf 34. Hassan RAM, Dória MT, Baracat EC, Filassi JR. Fatores preditivos de margens cirúrgicas comprometidas no tratamento do carcinoma ductal in situ da mama. Ver Bras Mastol. [Internet]. 2017 [cited Feb 8, 2017]; 27(1): 36-40. Available from: http://www.rbmastologia.com. br/wp-content/uploads/2017/01/MAS-v27n1_36-40.pdf
35. Pop-Bosui R, Boulton AJM, Fieldman EL, Bril V, Freeman R, Malik RA, et al. Diabetic Neuropathy: A Position Statement by the American Diabetes Association. Diabetes Care. [Internet]. 2017 [cited Jan 2, 2017]; 40:136-54. Available from: http://care. diabetesjournals.org/content/diacare/40/1/136.full.pdf 36. Stubbs B, Binnekade T, Eggermont L, Sepehry AA, Patchay S, Schofield P. Pain and the Risk for Falls in Community-Dwelling Older Adults: Systematic Review and Meta-Analysis. Arch Phys Med Rehabil. [Internet]. 2014 [cited May 16, 2016];95:175-87. Available from: http://www.archives-pmr.org/article/S00039993(13)00892-7/pdf

37. Day MA, Lang CP, Newton-John TRO, Ehde DM, Jensen MP. A content review of cognitive process measures used in pain research within adult populations. Eur ] Pain. [Internet]. 2017 [cited Feb 6, 2017]; 21:4560. Available from: http://onlinelibrary.wiley.com/ doi/10.1002/ejp.917/epdf

38. Luzia MF, Victor MAG, Lucena MF. Nursing Diagnosis Risk for falls: prevalence and clinical profile of hospitalized patients. Rev. Latino-Am. Enfermagem. [Internet]. 2014 [cited Feb 6, 2017]; 22(2):262-8. Available from: http://www.journals.usp.br/rlae/article/ view/85061/87906

39. Costa SGRF, Monteiro DR, Hemesath MP, Almeida MA. Caracterização das quedas do leito sofridas por pacientes internados em um hospital universitário. Rev Gaúcha Enferm. [Internet]. 2011 [Acesso 16 mai 2016];32(4):676-81. Disponível em: http://www.scielo. $\mathrm{br} / \mathrm{pdf} / \mathrm{rgenf} / \mathrm{v} 32 \mathrm{n} 4 / \mathrm{v} 32 \mathrm{n} 4 \mathrm{a} 06 . \mathrm{pdf}$

40. Vitor AF, Moura LA, Fernandes APNL, Botarelli FR, Araújo JNM, Vitorino ICC. Risk for falls in patients in the postoperative period. Cogitare Enferm. [Internet]. 2015 [cited Feb 6, 2017]; 20(1): 29-37. Available from: http:// revistas.ufpr.br/cogitare/article/view/38509/24834

41. Paiva MCMS, Paiva SAR, Berti HW, Campana AO. Characterization of patient falls according to the notification in adverse event reports. Rev Esc Enferm USP. [Internet]. 2010 [cited Feb 6, 2017]; 44(1):1348. Available from: http://www.scielo.br/pdf/reeusp/ v44n1/a19v44n1.pdf

42. Meneguin S, Ayres JA, Bueno GH. Caracterização das quedas de pacientes em hospital especializado em cardiologia. Rev Enferm UFSM. [Internet]. 2014 [Acesso 6 fev 2017]; 4(4):784-91. Disponível em: https:// periodicos.ufsm.br/reufsm/article/view/13554/pdf 43. Morais HCC, Holanda GF, Oliveira ARS, Costa AGS, Ximenes CMB, Araujo TL. Identificação do diagnóstico de enfermagem "risco de quedas em idosos com acidente vascular cerebral". Rev Gaúcha Enferm. [Internet]. 2012 [Acesso 6 fev 2017]; 33(2):117-24. Disponível em: http://www.scielo.br/pdf/rgenf/v33n2/17.pdf 
44. Chatterjee S, Chen $H$, Johnson ML, Aparasu RR. Risck of falls and fractures in older adults using atypical antipsychotic agents: a propensity score-adjusted, retrospective cohort study. Am J Geriatr Pharmacother. [Internet]. 2012 [cited Feb 6, 2017]; 10(2): 83- 94. Available from: http://www.sciencedirect.com/science/ article/pii/S1543594611001784

45. Castro IRS, Mendes RMAC, Guimarães MN, Carvalho LS, Santos EH, Fontes BV. Perfil de Quedas no Ambiente Hospitalar: a Importância das Notificações do Evento. Rev Acreditação: ACRED. [Internet]. 2011 [Acesso 6 fev 2017]; 1(2): 78-86. Disponível em: https://dialnet. unirioja.es/servlet/articulo?codigo $=5626534$

46. North American Nursing Diagnosis Association. Diagnósticos de enfermagem da NANDA: definições e classificação 2007- 2008. Porto Alegre: Artmed; 2007. $396 \mathrm{p}$. Creative Commons (CC BY).

This license lets others distribute, remix, tweak, and build upon your work, even commercially, as long as they credit you for the original creation. This is the most accommodating of licenses offered. Recommended for maximum dissemination and use of licensed materials. 